\title{
Functional Diversity of the Fish Community Associated to Soft-Bottoms in the Lagoon of La Paz B.C.S., México
}

\author{
Hernandez-Villasana Carlos Samuel1, Barjau-González Emelio ${ }^{*}{ }^{(0)}$, López-Vivas Juan Manuel1 (i), \\ Armenta-Quintana José Angel ${ }^{2}$ (i), Suárez-Villavicencio Jaime ${ }^{3}$ (i)

\begin{abstract}
${ }^{1}$ Departamento Académico de Ciencias Marinas y Costeras, Universidad Autónoma de Baja California Sur, La Paz, B.C.S. México ${ }^{2}$ Departamento Académico de Ciencia Animal y Conservación del Hábitat, Universidad Autónoma de Baja California Sur, La Paz, B.C.S., México

${ }^{3}$ Departamento Académico de Sistemas Computacionales, Universidad Autónoma de Baja California Sur, La Paz, B.C.S., México Email: cshv12345@gmail.com, ^ebarjau@uabcs.mx, jmlopez@uabcs.mx, jarmenta@uabcs.mx, jsuarez@uabcs.mx
\end{abstract}

How to cite this paper: Samuel, H.-V.C., Emelio, B.-G., Manuel, L.-V.J., Angel, A.-Q.J. and Jaime, S.V. (2020) Functional Diversity of the Fish Community Associated to Soft-Bottoms in the Lagoon of La Paz B.C.S., México. Open Journal of Marine Science, 10, 233-244.

https://doi.org/10.4236/ojms.2020.104018

Received: August 3, 2020

Accepted: October 9, 2020

Published: October 12, 2020

Copyright $\odot 2020$ by author(s) and Scientific Research Publishing Inc. This work is licensed under the Creative Commons Attribution International License (CC BY 4.0).

http://creativecommons.org/licenses/by/4.0/ (c) (i) Open Access

\begin{abstract}
There has been an increase of community studies that incorporate the use of functional diversity indices. The incorporation of these indices in the analysis of marine communities is recent, however, could contribute with relevant information about the health of those communities. The lagoon of La Paz is a body of water located in La Paz, B.C.S., México. Despite its regional importance, there are not recent studies about its fish communities. Therefore, the aim of the present study was to analyze the temporal and spatial structure of the functional diversity of fish communities associated to soft bottoms, from August 2016 to July 2017, as well as important environmental variables. Functional diversity indices showed significant differences between months. Spatial analysis did not show significant differences perhaps due to low variability of the type of substrate. Temperature showed temporal differences as well. Therefore, temperature may be a limiting environmental variable for many fish species inhabiting coastal lagoons.
\end{abstract}

\section{Keywords}

Coastal Lagoon, Functional Diversity, Functional Traits, Fish Community

\section{Introduction}

Coastal lagoons are one of the most productive ecosystems on the planet. They support important fisheries, and some are under extensive and intense exploitation. Their particular characteristics, such as shallowness, relative isolation from 
the sea and high biomass of organic matter [1], help to explain its high productivity.

The transitional nature of coastal lagoons (between terrestrial and marine ecosystems) makes lagoons located on the South of the Baja California peninsula, particularly vulnerable to anthropogenic impact and natural input of freshwater and soil [2].

Fish species inhabiting coastal lagoons must be able to tolerate environmental stress by showing particular life histories or by taking advantage of seasons when environmental variables are favourable.

Functional diversity is important to understand ecosystem processes [3] [4] [5] [6] and determines their resistance to environmental change [7]. The analysis of functional traits helps to understand adaptation of organisms to a specific ecosystem [8]. Functional diversity is an excellent indicator of the vulnerability of certain species [9] [10] [11] [12] because it helps to determine which traits could resist or be vulnerable to environmental change. Villeger et al. [13] designed the functional diversity indices (FRic, FEve and FDiv) used in this study. These indices have been widely used in fish community studies [14] [15]. Many authors have concluded that anthropogenic impact, as well as biotic and abiotic factors, influences functionality of fish communities, founding a decrease of functional diversity in disturbed habitats. Therefore, the aim of the present study was to analyze the temporal and spatial structure of the functional diversity of fish communities associated to soft bottoms in the lagoon of La Paz, B.C.S.

\section{Methods}

The coastal lagoon of La Paz (Figure 1) is located in the state of Baja California Sur, México, on the southwest area of La Paz Bay between the parallels $24^{\circ} 11^{\prime}$ and $24^{\circ} 06^{\prime}$, and between meridians $110^{\circ} 19^{\prime}$ and $110^{\circ} 25^{\prime}$. It is separated from the main body of La Paz Bay by a sand barrier known as "El Mogote" measuring 11 $\mathrm{km}$ of length and $2.7 \mathrm{~km}$ on the widest part [16].

Collection of fish specimens was carried out from August 2016 to July 2017, with six samplings carried out every two months in seven localities (Table 1), given a total of 42 replicates. Localities were selected based on bathymetry and type of sediment. Collection was carried out using an experimental trawl net with a length of $9.5 \mathrm{~m}$, a vertical opening of $4.5 \mathrm{~m}$, and a mesh size of $4.44 \mathrm{~cm}$ (1.75 inches). Trawling was carried out by a 22 feet boat with a 75 HP four stroke outboard motor, at a speed of $3.5 \mathrm{~km} / \mathrm{h}$ and sweeps that lasted 20 minutes, at an average depth of $5 \mathrm{~m}$.

Fish specimens were analysed at Laboratory of Fish Ecology at Autonomous University of Baja California Sur. Processing of samples consisted on determination of morphometric measurements and weight. Species identification was carried out using specialized literature. All fish specimens were preserved using $10 \%$ formaldehyde followed by $70 \%$ ethanol.

Environmental variables 


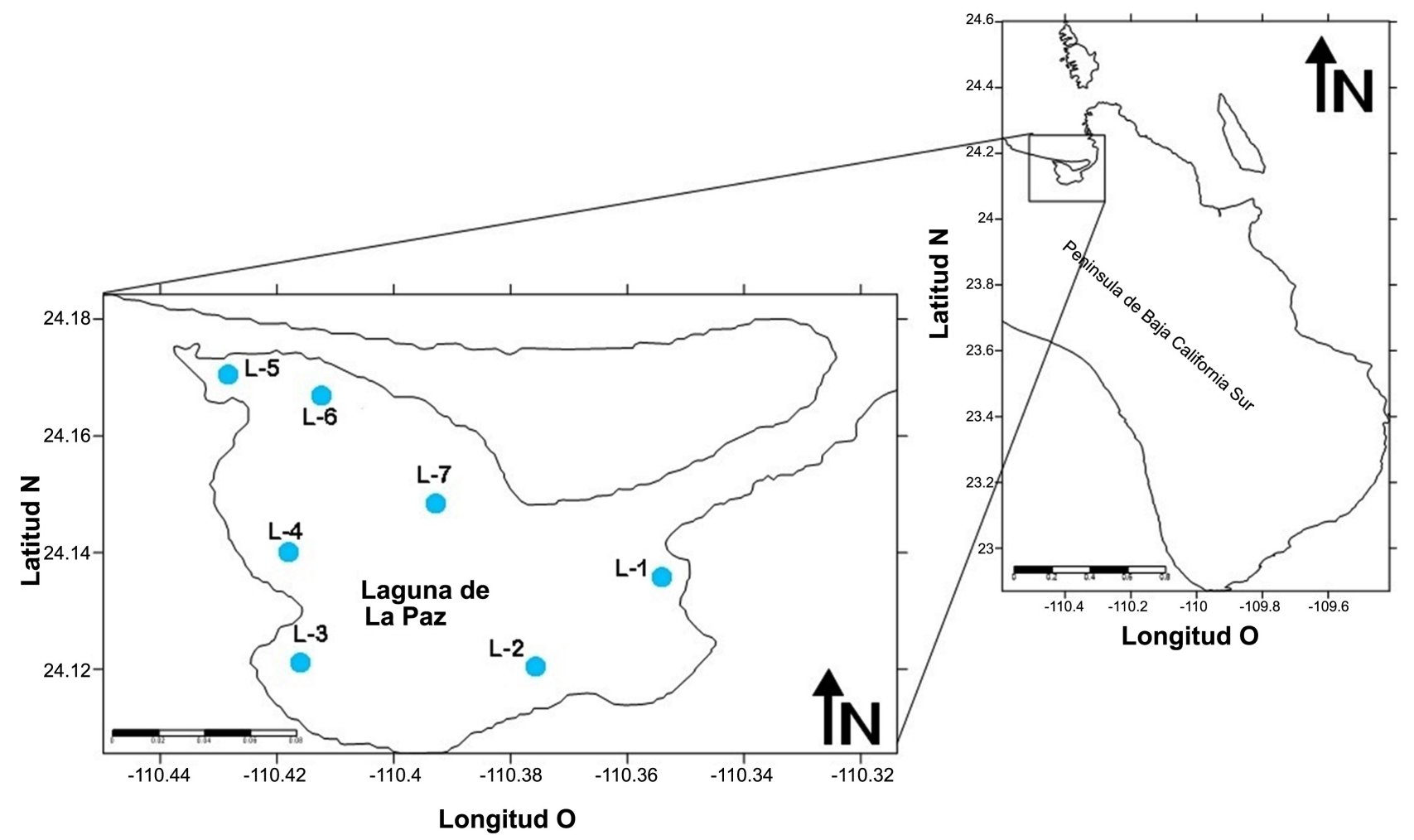

Figure 1. Geographic location of the study area (lagoon of La Paz, B.C.S.) and sampling localities. Grand Plaza (L-1), Aeropuerto (L-2), Aripez (L-3), Cibnor (L-4), Zacatecas (L-5), Las Palmas (L-6), Yate Hundido (L-7).

Table 1. Coordinates of the sampling localities in the lagoon of La Paz, B.C.S.

\begin{tabular}{ccc}
\hline Localities & $\mathrm{N}$ & $\mathrm{W}$ \\
\hline L-1 Grand Plaza & 2407.816 & 11021.480 \\
L-2 Aeropuerto & 2407.264 & 11023.354 \\
L-3 Aripez & 2407.243 & 11025.081 \\
L-4 Cibnor & 2408.368 & 11024.859 \\
L-5 Zacatecas & 2410.152 & 11025.627 \\
L-6 Las Palmas & 2409.697 & 11024.338 \\
L-7 Yate Hundido & 2408.851 & 11023.779 \\
\hline
\end{tabular}

Water temperature $\left({ }^{\circ} \mathrm{C}\right)$, dissolved oxygen and salinity (UPS) were recorded at each locality using a YSI 2030 Pro multiparameter instrument, at an average depth of $5 \mathrm{~m}$ (determined using a Secchi disk), at the same time of day during each sampling.

Functional diversity analysis included the following traits: type of teeth and type of mandible (determined during species identification), type of diet, trophic level, species resilience and species status (obtained from FishBase). Functional group determination was based on [16]. Uncategorised functional groups were standardized with a binary system $1 / 0$ according to presence/absence of a trait.

Functional richness 
Functional richness (FRci) refers to the space occupied by a group of traits in the multivariate space (hyperspace). This index, as well as convex hull volume, identifies traits with extreme values and then estimates the space occupied by the group of traits. The algorithm allows a standardization by avoiding effects of scale and carries out a transformation when the number of traits is equal or higher than the number of species, allowing a reduction of dimensionality. This transformation makes the range of the matrix equal or lower than the range of the column, enabling the calculation of the convex hull. The highest value possible of FRci in a space of $\mathrm{T}$ dimensions with $2 \mathrm{~T}$ species, is obtained by the combination of extreme values (minimum and maximum) of all traits [17].

Functional evenness

Functional evenness (FEve) describes the distribution of abundances of functional traits in the multivariate space. This index uses the relative abundances of species [18]. FEve values range between 0 and 1 , values closer to 1 when all species are equally represented, inferring a heterogeneity of traits with an evenly distributed abundance, and values closer to 0 when species have very high or very low values of density, or when species with higher abundances have low richness of functional traits [19]. FEve is not affected by species richness.

$$
\text { FEve }=\frac{\sum_{b=1}^{S-1} \min \left(\mathrm{PWE}_{b}, \frac{1}{S-1}\right)-\frac{1}{S-1}}{1-\frac{1}{S-1}}
$$

where $\mathrm{PEW}_{b}$ is the weighted evenness, $S-1$ are the segments of the tree (in the multivariate space), $(1 /(S-1))$ is the quantification of discrepancy of the final value.

\section{Functional divergence}

Functional divergence (FDiv) measures the distribution of abundances in the occupied functional space and the irregularity of that distribution. This index measures if species with traits located closer to the centre of gravity of the multivariate space, where traits act as coordinates, are the most abundant. The centre of gravity is calculated without accounting for relative abundances [18]. Therefore, indicating if species with common traits are also the most abundant species. The value of FDiv ranges between 1 and 0 , with lower values closer to 0 when functional traits of dominant species are closer to the centre of the multivariate space. Lower values of functional divergence are linked with a lower degree of niche differentiation in highly competitive communities. On the contrary, higher values of functional divergence, closer to 1, when abundant species have functional traits located further away from the centre of gravity of the multivariate space, are linked to a high degree of niche differentiation in lower competitive communities.

$$
\operatorname{FDiv}=\frac{\Delta d+\overline{d G}}{\Delta|d|+\overline{d G}}
$$

where $(\Delta d)$ and $\Delta|d|$ are weighted deviations, $\overline{d G}$ is the average distance of the 
$S$ species to the centre of gravity.

\section{Functional dispersion}

Functional dispersion (FDis) is the average distance of species from the centre of gravity of the functional space, considering relative abundances. This index describes the degree of heterogeneity of functional traits of a community [19] [20].

High values of functional dispersion are expected when there is an increment of ecological processes, since those produce a higher differentiation of the ecosystem. This will drive species to a higher differentiation to avoid competition between them. Therefore, a high FDis value indicates an adaptation of the organisms to the ecosystem, perhaps indicating some kind of resistance to invasive species, since the majority of the niche spaces are occupied. On the contrary, if species are missing, there could be a high loss of functional diversity since a high functional dispersion indicates that some of the functions of the ecosystem are linked to a reduced number of species.

$$
\text { FDis }=\sum_{i=1}^{S} w_{i} z_{i}
$$

where $W_{i}$ is the relative abundance of the $i$ th species and $Z_{i}$ is the distance of the ith species to the weighted centroid. This method moves the position of the centroid towards species with higher abundance and weights the individual distance of each species based on its relative abundance [20].

Functional diversity indices were calculated using the software FDiversity. Normality and homocedasticity tests were carried out prior to spatial and temporal statistical analysis. Differences of the functional diversity indices between months and localities were determined by one way ANOVA. All statistical analysis were carried out using the software Statistica v 10.0.

\section{Results}

A total of 2763 organisms were collected, belonging to the following families: Scianidae, Gerreidae, Urotrygonidae, Paralichtydae and Serranidae, with a total biomass of $221.466 \mathrm{~kg}$ and an individual average weight of $80.18 \mathrm{~g}$.

\section{Environmental variables}

Temperature was not significantly different between localities $(\mathrm{F}(6,35)=\mathrm{p}=$ $0.22)$. Lowest temperature was recorded in Zacatecas $\left(23.28^{\circ} \mathrm{C}\right)$, and the highest was recorded at Gran Plaza $\left(25.42^{\circ} \mathrm{C}\right)$. On the contrary, comparison between months showed significant differences $(F(5,36)=10.1685)$. Two climate seasons were defined, a warm season from August to October, and a cold season from December to February (Table 2).

Salinity was not significantly different between localities $(\mathrm{F}(6,35)=\mathrm{p}=$ 0.8276). Lowest salinity was recorded at Gran Plaza (31.75 UPS) and the highest was recorded at Cibnor (33.68 UPS). Likewise, comparison between months did not show significant differences $(F(5,36)=p=0.6898)$. The highest value was recorded in October (33.97 UPS) and the lowest value was recorded in April (31.90 UPS) (Table 2). 
Table 2. Summary of the environmental variables and functional diversity indices measured at each sampling locality and month: temperature $\left(\mathrm{T}^{\circ} \mathrm{C}\right)$, salinity (UPS), dissolved oxygen (DO), Functional richness (Fric), functional evenness (Feve), functional divergence (Fdiv), functional dispersion (FDis).

\begin{tabular}{cccccccc}
\hline Localities and months & $\mathrm{T}^{\circ} \mathrm{C}$ & UPS & DO & FRic & FEve & FDiv & FDis \\
\hline L-1 & 25.42 & 31.78 & 19.32 & 7.40 & 0.35 & 0.66 & 2.32 \\
L-2 & 23.70 & 33.60 & 19.13 & 18.3 & 0.47 & 0.65 & 2.18 \\
L-3 & 24.17 & 33.32 & 19.18 & 20.17 & 0.63 & 0.88 & 3.02 \\
L-4 & 24.07 & 33.68 & 19.68 & 3.63 & 0.68 & 0.74 & 3.45 \\
L-5 & 23.28 & 32.02 & 18.39 & 0.06 & 0.49 & 0.74 & 3.45 \\
L-6 & 24.23 & 33.33 & 20.46 & 7.7 & 0.38 & 0.65 & 1.81 \\
L-7 & 24.18 & 33.67 & 21.25 & 2.75 & 0.57 & 0.86 & 2.50 \\
August & 28.17 & 33.30 & 12.44 & 6.85 & 0.67 & 0.85 & 3.25 \\
October & 26.74 & 33.97 & 21.6 & 6.59 & 0.46 & 0.76 & 2.41 \\
December & 22.71 & 33.19 & 20.28 & 18.40 & 0.29 & 0.45 & 1.35 \\
February & 21.43 & 32.77 & 21.31 & 11.93 & 0.41 & 0.79 & 2.27 \\
April & 23.04 & 31.90 & 21.22 & 4.85 & 0.57 & 0.84 & 3.10 \\
June & 22.80 & 33.21 & 21.92 & 2.83 & 0.66 & 0.79 & 3.14 \\
\hline
\end{tabular}

Dissolved oxygen was not significantly different between localities $(\mathrm{F}(6,35)=$ $\mathrm{p}=0.3425)$. The lowest value was recorded at Zacatecas $(18.5 \mathrm{ml} / \mathrm{l})$, and the highest value was recorded at Yate Hundido $(21.5 \mathrm{ml} / \mathrm{l})$. On the contrary, comparison between months showed significant differences $(F(5,36)=p=23.819)$, recording the lowest value during August (12.5 ml/l) (Table 2).

\section{Functional richness}

Comparison of functional richness between localities did not show significant differences $(F(5,36)=p=0.5809)$. Likewise, temporal comparison did not show significant differences $(\mathrm{F}(6,35)=\mathrm{p}=0.9762)$. However, there was an increase during the cold months, December and February. Although there were not significant differences between months and localities, FRic values by localities were lower than the monthly values (Table 2).

\section{Functional evenness}

Comparison of functional evenness between localities did not show significant differences $(F(6,35)=p=1.8415)$. The highest value was recorded at Cibnor (0.68), and the lowest value was recorded at Gran Plaza (0.35). Temporal comparison showed significant differences $(F(5,36)=p=4.0298)$. The highest value was recorded in August (0.67), while the lowest value was recorded in December (0.29). The majority of the FEve values by localities and months were close to or above 0.5 , indicating an even distribution of traits (Table 2).

\section{Functional divergence}

Comparison of functional divergence between localities did not show significant differences $(F(6,35)=p=1.0975)$. The highest value was recorded at 
Arizpe (0.88), and the lowest value was recorded at Aeropuerto (0.65). On the contrary, temporal comparison showed significant differences $(\mathrm{F}(5,36)=\mathrm{p}=$ 3.7833), with the highest value recorded in August (0.85) and the lowest value recorded in December (0.45) (Table 2).

\section{Functional dispersion}

Comparison of functional dispersion between localities did not show significant differences $(\mathrm{F}(6,35)=\mathrm{p}=1.6211$. The highest value was recorded at Zacatecas (3.45), and the lowest value was recorded at Las Palmas (1.81). On the contrary, temporal comparison showed significant differences $(\mathrm{F}(5,36)=\mathrm{p}=4.1434$, with the highest value recorded in August (3.25) and the lowest value recorded in December (1.35).

\section{Discussion}

\section{Environmental variables}

Temperature and salinity did not show temporal or spatial differences, only dissolved oxygen showed a significant difference between months. Temperature showed an increment towards the summer months. In addition, there was a positive correlation between temperature and salinity, with August as the warmer month, as well as the one with the highest salinity. There was also a negative correlation between temperature and dissolved oxygen, so that with higher temperature, low values of dissolved oxygen were recorded, consistent with previous data reported by Barjau-González et al., [21]. These environmental variations are linked to the bathymetry of the lagoon. According to Aguirre [22], the shallow areas facilitate evaporation, therefore increasing temperature. He reported June and August as the warmer months. Contrary to what is described in the present study, in which August and October are reported as the warmer months, perhaps linked to the change of bathymetry in the lagoon and/or oceanographic events like El Niño Southern Oscillation (ENSO). Another factor could be the slower currents $\left(2-4 \mathrm{~cm} \cdot \mathrm{s}^{-1}\right)$ [23], which together with the shallowness of the area and solar incidence, could facilitate a rise of temperature and a decrease of dissolved oxygen during the summer months [24].

\section{Functional richness}

Functional richness did not show significant differences between localities and months. For its interpretation, we are adopting the same interpretation as Homar [25] [26], values below 20 indicate low functional richness, values between 20 and 40 indicate moderate richness, values between 41 and 60 indicate moderately high richness, and values above 60 indicate high richness. Regarding comparison between localities, the highest value of FRi was recorded at Arizpe (20.17), considered as moderate richness. Aeropuerto was the only locality with a value corresponding to a moderately high functional richness (18.3). The remaining localities showed FRi values considered as low richness. Regarding temporal comparison, December registered the highest value of functional richness, followed by February. However, the rest of the months registered low val- 
ues of this index. Francisco y De la Cueva [27] mentioned that functional richness represents the space occupied by an assembly, in other words, it groups different traits according to species, and calculates the space occupied by those. The ecological meaning of this index is that it measures the diversity of the traits according to species, therefore, number of traits cannot be higher than the number of species [28].

\section{Functional evenness}

Functional evenness did not show significant spatial differences; however, the highest values are above 0.6 , indicating that at least one of the samplings showed a moderate heterogeneity, similar to values recorded during temporal analysis, apart from December, which recorded the lowest value, indicating homogeneity of functional traits. This index can be compared to Margalef's richness index, which is used to evaluate diversity based on abundance and determines a possible dominance. A functional evenness value closer to 0 indicates a highly heterogeneous space, therefore, dominance of a trait is higher in warm waters, as well as the dominance of a species. Extreme abundances, either very low or very high values are characteristic of functional evenness values closer to 0 [29].

Temporal differences could be linked to temperature, in warmer climates there is an increase of homogeneity of traits, which infers there are few different traits despite of the high number of species. Unlike December, when homogeneity was low, inferring that perhaps during this month, there are more specialist species with very different traits despite of the low number of species that used the lagoon as a shelter.

\section{Functional divergence}

Functional divergence did not show significant spatial differences, however, all localities registered values above 0.6, perhaps indicating traits with extreme values, assuming traits in these localities tend to be less common. Therefore, no difference of traits between localities. On the contrary, Homar [25] reported that localities and type of substrate have an effect on functional divergence, which could become irrelevant factors to consider for the lagoon of La Paz, perhaps due to differences between open and coastal areas. In addition, the lagoon of La $\mathrm{Paz}$ is a highly productive area due to mangrove swamps, which act as shelter and breeding areas for many fish species. Comparison between months showed high values of functional divergence, possibly reflecting the variability and/or divergence of traits of abundant species [30]. These values are possibly linked to environmental variables, since these are usually the limiting factors for many species.

\section{Functional dispersion}

Functional dispersion did not show significant differences between localities; however, Zacatecas registered the highest value (4.7), followed by Arizpe (4.4). These values indicate that these localities have a high number of ecological processes compared to the remaining localities. There are no previous studies based on this index that allows for comparison of this type of ecosystems. However, the localities with higher values of functional dispersion are associated to 
wetlands, where important ecological processes are carried out, such as $\mathrm{CO}_{2}$ sequestration [24] [31].

Temporal analysis of this index showed significant differences. December registered the lower value of functional dispersion, perhaps indicating that during the colder months there is a decrease of ecological processes $\left(\mathrm{CO}_{2}\right.$ sequestration), possibly linked to temperature [30]. The majority of ecological processes are associated to tropical areas, particularly mangrove swamps and coral reefs. The highest values of functional dispersion were recorded during August, April and June, which is similar to that reported by González et al., [31].

There is an inconvenience with this index when it comes to its interpretation. There are no ranges, or upper or lower limits [22]. The only interpretation is that there is a positive correlation between functional dispersion and number of ecological processes that produce a higher differentiation of the ecosystem, therefore, influencing a specialization of species, reducing competition. According to this and based on our results, there is a moderate dispersion of functional traits, characteristic of a semi-vulnerable ecosystem, facing loss of species and possible replacement of those by invasive species. This vulnerability can be attributed directly to the anthropogenic impact on the lagoon, particularly by the dredging of the bottom and spilling of sewage water for many years.

It is important to continue studying the fish communities of the lagoon of $\mathrm{La}$ $\mathrm{Paz}$, to be able to have a better understanding of the variation of the functional diversity, since the present study only showed a year of data. In addition, it is important to increase the use of quantitative traits to enable an efficient analysis of the effect of environmental variables on functional diversity.

\section{Conclusions}

Environmental parameters showed temporal variation that had an effect on the diversity of organisms, with temperature as a limiting factor. Because salinity and dissolved oxygen are dependent on temperature, fish species distribution could potentially be limited by bodies of water with different temperatures, rather than salinity or dissolved oxygen.

Functional evenness (FEve) and functional divergence (FDiv) could potentially be used as tools for the analysis of marine communities, as they serve as good complements to the traditional ecological indices, due to the biologic interpretation.

\section{Authors' Contributions}

CSHV co-wrote the manuscript with EBG. EBG carried out fish collection and ID and analyzed data. AKRP, JMLV and JSV contributed to revisions, All authors read and approved the final manuscript. Likewise, they declare no conflict of interest.

\section{Acknowledgements}

Authors would like to thank Autonomous University of Baja California Sur 
(UABCS) for allowing the use of its facilities (Laboratorio de Ecología de Peces) and boat. Bruma R. Castillo Rosas for providing the figures. M.Sc. Myrna Barjau Pérez Milicua for the English editing of the manuscript.

\section{Conflicts of Interest}

The authors declare no conflicts of interest regarding the publication of this paper.

\section{References}

[1] Escobedo-Urías, D., Martínez-López, A., Jiménez-Illescas, A., Ulloa-Pérez, A.E. and Zavala-Norzagaray, A. (2007) Intercambio de carbono orgánico particulado del sistema lagunar San Ignacio-Navachiste, Sinaloa, con el mar adyacente. Carbono en sistemas acuáticos de México. INE-CICESE, México, 171-185.

[2] Pérez, R.A., Concepcion, M., Pérez, R.M. and Pérez, M.M. (2013) Are Coastal Lagoons Physically or Biologically Controlled Acosystems? Revisiting R vs K Strategies in Coastal Lagoons and Estuaries. Estuarine, Coastal and Shelf Science, 132, 17-33. https://doi.org/10.1016/j.ecss.2012.04.011

[3] Loreau, M. (1998) Biodiversity and Ecosystem Functioning: A Mechanistic Model. Procedings of the National Academy of Sciences USA, 95, 5632-5636. https://doi.org/10.1073/pnas.95.10.5632

[4] Chapin, F.S., Zavelata, E.S., Eviner, V.T., Naylor, R.L., Vitousek, P.M., Reynolds, H.L., Hooper, D.U., Lavorel, S., Sala, O.E., Hobbie, S.E., Mack, M.C. and Diaz, S. (2000) Consequences of Changing Biodiversity. Nature, 405, 234-242. https://doi.org/10.1038/35012241

[5] Tilman, D. (2000) Causes, Consequences and Ethics of Biodiversity. Nature, 405, 208-211. https://doi.org/10.1038/35012217

[6] Díaz, S. and Cabido, M. (2001) Vive la Difference: Plant Functional Diversity Matters to Ecosystem Processes. Trends Ecology Evolution, 16, 646-655. https://doi.org/10.1016/S0169-5347(01)02283-2

[7] Folke, C., Carpenter, S., Walker, B., Scheffer, M., Elmqvist, T., Gunderson, L. and Holling, C.S. (2004) Regime Shifts, Resilience and Biodiversity in Ecosystem Management. Annual Review of Ecology Evolution and Systematics, 35, 557-581. https://doi.org/10.1146/annurev.ecolsys.35.021103.105711

[8] Sanquist, D.R. and Cordell, S. (2007) Functional Diversity of Carbon-Gain, Water-Use, and Leaf-Allocation Traits in Trees of a Threatened Lowland Dry Forest in Hawaii. American Journal of Botany, 94, 1459-1469. https://doi.org/10.3732/ajb.94.9.1459

[9] Loreau, M., Naeem, S., Inchausti, P., Bengtsson, J., Grime, J.P., Hector, A., Hooper, D.U., Huston, M.A., Raffaelli, D., Schmid, B., Tilman, D. and Wardle, D.A. (2001) Biodiversity and Ecosystem Functioning: Current Knowledge and Future Challenges. Science, 294, 804-808. https://doi.org/10.1126/science.1064088

[10] Hooper, D.U., Chapin III, F.S., Ewel, J.J., Hector, A., Inchausti, P., Lavorel, S., Lawton, J.H., et al. (2005) Effects of Biodiversity on Ecosystem Functioning: A Consensus of Current Knowledge. Ecological Monographs, 75, 3-35. https://doi.org/10.1890/04-0922

[11] Tilman, D. (1997) Distinguishing between the Effects of Species Diversity and Species Composition. Oikos, 80, 185. https://doi.org/10.2307/3546532 
[12] Hulot, F.D., Lacroix, G., Lescher-Moutoue, F.O. and Loreau, M. (2000) Functional Diversity Governs Ecosystem Response to Nutrient Enrichment. Nature, 405, 340-344. https://doi.org/10.1038/35012591

[13] Villeger, S., Mason, N.W.H. and Mouillot, D. (2008) New Multidimensional Functional Diversity Indices for a Multifaceted Framework in Functional Ecology. Ecology, 89, 2290-2301. https://doi.org/10.1890/07-1206.1

[14] Dolbeth, M., Vendel, A.L., Pessanha, A. and Patrício, J. (2016) Functional Diversity of Fish Communities in Two Tropical Estuaries Subjected to Anthropogenic Disturbance. Marine Pollution Bulletin, 112, 244-254. https://doi.org/10.1016/j.marpolbul.2016.08.011

[15] Colin, N., Villéger, S., Wilkes, M., de Sostoa, A. and Maceda-Veiga, A. (2018) Functional Diversity Measures Revealed Impacts of Non-Native Species and Habitat Degradation on Species-Poor Freshwater Fish Assemblages. Science of the Total Environment, 625, 861-871. https://doi.org/10.1016/j.scitotenv.2017.12.316

[16] Heemsbergen, D.A., Berg, M.P., Loreau, M., Van Hal, J.R., Faber, J.H. and Verhoef, H.A. (2004) Biodiversity Effects on Soil Processes Explained by Interspecific Functional Dissimilarity. Science, 306, 1019-1020.

https://doi.org/10.1126/science.1101865

[17] Mason, N.W.H., Mouillot, D., Lee, W.G. and Wilson, J.B. (2005) Functional Richness, Functional Evenness and Functional Divergence: The Primary Components of Functional Diversity. Oikos, 111, 112-118. https://doi.org/10.1111/j.0030-1299.2005.13886.x

[18] Anderson, M.J. (2006) Distance-Based Tests for Homogeneity of Multivariate Dispersions. Biometrics, 62, 245-253. https://doi.org/10.1111/j.1541-0420.2005.00440.x

[19] Laliberté, E. and Legendre, P. (2010) A Distance-Based Framework for Measuring Functional Diversity from Multiple Traits. Ecology, 91, 299-305. https://doi.org/10.1890/08-2244.1

[20] Vega, C.M.E. and Hernandez, S.M. (2004) Fish Community Structure and Dynamics in a Coastal Hypersaline Lagoon: Rio Lagartos, Yucatan, Mexico. Estuarine Coastal and Shelf Science, 60, 285-299. https://doi.org/10.1016/j.ecss.2004.01.005

[21] Barjau, G.E., Armenta, Q.J.Á., Romo, P.A.K. and López, V.J.M. (2018) Taxonomic Distinctness of the Soft-Bottom Fish Community in a Coastal Lagoon of the West Coast of the Gulf of California, México. International Journal of Marine Science, 8, 106-113.

[22] Aguirre Bahena, F. (2002) Dinámica de los componentes de la materia particulada suspendida y otras variables hidrológicas en la Ensenada-Bahía de La Paz, Baja California Sur, México. Doctoral Dissertation, Instituto Politécnico Nacional. Centro Interdisciplinario de Ciencias Marinas.

[23] Sandoval, M., et al. (1997) Tides and Tidal in Ensenada de la paz Baja California Sur Mexico. Geofisica Internacional, 39, 37-47.

[24] Green, R. and Larrinaga, H. (1986) Sedimentología y geoquímica de la laguna de La Paz B.C.S, México tesis de licenciatura UABCS, La Paz, México. 83 p.

[25] Homar Rosselló, A. (2018) Comparación de diversidad funcional en comunidades de peces de plataforma de dos ecosistemas del Mediterráneo Occidental.

[26] Jimenez illescas, A., Obesinieblas, M. and Salas de Leon, D.A. (1997) Oceanografía física de la bahía de la Paz, B.C.S., 31-41.

[27] Francisco, V. and de la Cueva, H. (2017) Nuevas perspectivas en la diversidad funcional de ambientes marinos. Latin American Journal of Aquatic Research, 45, 261-275. 
https://doi.org/10.3856/vol45-issue2-fulltext-3

[28] Kang, B., Huang, X., Yan, Y., Yan, Y. and Lin, H. (2018) R Language-Based Methods for Revealing Taxonomic and Functional Diversity and Tracing Process of Fish Fauna. MethodsX, 5, 1498-1502. https://doi.org/10.1016/j.mex.2018.11.003

[29] Gray, C.A., Rotherham, D. and Johnson, D.D. (2011) Consistency of Temporal and Habitat-Related Difference among Assemblages of Fish in Coastal Lagoons. Estuarine, Coastal and Shelf Science, 95, 401-413. https://doi.org/10.1016/j.ecss.2011.10.010

[30] Jiménez-Ramón, J.A. (1999) Los humedales de América Central: Su importancia ecológica y económica. WWF Centroamérica, 2, 4-6.

[31] González, A.A.F., De la Cruz, A.J., De la Cruz, A.G. and Ruiz-Campos, G. (1999) Ictiofauna asociada al manglar del estero el Conchalito, ensenada de La Paz, Baja California Sur, México. 